\title{
Urinary excretion of the metabolites of n-hexane and its isomers during occupational exposure
}

\author{
L PERBELLINI, ${ }^{1}$ F BRUGNONE, ${ }^{1}$ AND G FAGGIONATO ${ }^{2}$ \\ From the Institute of Occupational Medicine, ${ }^{1}$ University of Padua-Verona, and the Service of \\ Occupational Medicine, ${ }^{2} S$ Bonifacio, Verona, Italy
}

ABSTRACT Environmental exposure to commercial hexane (n-hexane, 2-methylpentane, and 3methylpentane) was tested in several work places in five shoe factories by taking three grap-air samples during the afternoon shift. Individual exposure ranges were $32-500 \mathrm{mg} / \mathrm{m}^{3}$ for $\mathrm{n}$-hexane, $11-250 \mathrm{mg} / \mathrm{m}^{3}$ for 2-methylpentane, and $10-204 \mathrm{mg} / \mathrm{m}^{3}$ for 3-methylpentane. The metabolites of commercial hexane in the urine of 41 workers were measured at the end of the work shift. 2-Hexanol, 2,5-hexanedione, 2,5-dimethylfuran, and $\gamma$-valerolactone were found as $n$-hexane metabolites and 2-methyl-2-pentanol and 3-methyl-2-pentanol as 2-methylpentane and 3-methylpentane metabolites. The presence of metabolites in the urine was correlated with occupational exposure to solvents. n-Hexane exposure was correlated more positively with 2-hexanol and 2,5-hexanedione than with 2,5-dimethylfuran and $\gamma$-valerolactone. A good correlation was also found between total n-hexane metabolites and n-hexane exposure. 2-Methyl-2-pentanol and 3-methyl-2-pentanol were highly correlated with 2-methylpentane and 3-methylpentane exposure. The results suggest that the urinary excretion of hexane metabolites may be used for monitoring occupational exposure to n-hexane and its isomers.

Occupational exposure to commercial hexane (which contains n-hexane, 2-methylpentane, and 3-methylpentane) may be studied by means of environmental, alveolar, and blood tests ${ }^{2}{ }^{2}$ but not by urinary tests, although research carried out on shoe factory workers exposed to commercial hexane has shown that numerous biotransformation compounds are excreted in the urine at the end of the work shift. ${ }^{3}$

2,5-Hexanedione, 2-hexanol, $\gamma$-valerolactone, and 2,5-dimethylfuran were found in connection with n-hexane exposure and 2-methyl-2-pentanol and 3-methyl-2-pentanol in connection with 2methylpentane and 3-methylpentane exposure. The identification of these compounds in the urine of workers exposed to commercial hexane prompted us to test their urinary excretion to see if any correlation exists between environmental solvent exposure and metabolite excretion.

\section{Materials and methods}

REAGENTS

The following products were used to detect urinary

Requests for reprints to: Dr Luigi Perbellini, Istituto di Medicina del Lavoro, Policlinico Borgo Romo, 37100-Verona, Italy.

Received 15 February 1980

Accepted 2 May 1980 metabolites: 2-methyl-2-pentanol, 3-methyl-2-pentanol, 2-hexanol, 2,5-hexanedione, 2,5-dimethylfuran, $\gamma$-valerolactone, trichloroethanol, and cyclohexanone. 2-Methyl-2-pentanol, 3-methyl-2-pentanol, 2,5dimethylfuran and trichloroethanol were obtained from Aldrich Chemical Co, Milwaukee, Wis, USA; 2,5-hexanedione from Eastman Kodak Co, Rochester, New York; 2-hexanol and $\gamma$-valerolactone from Merck, Schuchardt, Honenbrunn; cyclohexanone, used as internal standard, from C Erba, Milan; and the "suc d'helix pomatia" containing $100000 \mathrm{U}$ of $\beta$-glucuronidase (Fishman) from Pharmindustrie IBF, Clichy.

ENVIRONMENTAL AND URINARY SAMPLING Environmental solvent levels were measured at several work places in five shoe factories. In each work place three grap samples were taken from the breathing zone of workers during the afternoon shift. Workers stayed in their places during the whole shift. The air samples were taken by a manual pump into $75-\mathrm{ml}$ glass tubes stoppered with screw caps with a Teflon septum at each end. The solvent concentrations of air samples were determined by gas chromatography within four hours of sampling time, as previously described. ${ }^{1}$

At the end of the afternoon shift, samples of urine were collected from 41 workers whose en- 
vironmental hexane exposure had been determined. The metabolites of hexane were tested in the urine samples, which were kept at $-25^{\circ} \mathrm{C}$ until test time.

\section{URINE ANALYSIS}

Ten millilitres of urine placed in glass tubes stoppered with Teflon screw caps and adjusted to a pH 4.8 with $\mathrm{HCl}$, were treated with $100 \mu \mathrm{l}$ of $\beta$-glucuronidase. After an incubation of 24 hours at $37^{\circ} \mathrm{C}$, the urine sample was adjusted to $\mathrm{pH} 2$ with $\mathrm{HCl}$ and heated for $30 \mathrm{~min}$ in a steam bath. After cooling at room temperature, cyclohexanone $(19 \mu \mathrm{g})$ as internal standard, and dichloromethane $(3 \mathrm{ml})$ were added. The sample was shaken for one hour and then centrifuged for $15 \mathrm{~min}$. The solvent recovered $(80-90 \%$ of the amount added) was evaporated to $0.3 \mathrm{ml}$ with a nitrogen flow and then injected into a gas chromatograph. The urinary metabolites of hexane were identified on the basis of gas chromatographic retention time, and their mass spectra were compared with those of authentic samples. $^{3}$

\section{CALIBRATION CURVE OF URINARY}

METABOLITES

Standard solutions of 2-hexanol, 2,5-hexanedione, 2-methyl-2-pentanol, 3-methyl-2-pentanol, 2,5-dimethylfuran, and $\gamma$-valerolactone were prepared in dichloromethane. Increasing amounts of the products were added to $10 \mathrm{ml}$ of control urine adjusted to $\mathrm{pH} 2$. After addition of cyclohexanone $(19 \mu \mathrm{l})$ and dichloromethane $(3 \mathrm{ml})$, the samples were shaken and centrifuged as described above. The following minimum concentrations of metabolites were detectable: 2-hexanol, 2-methyl-2-pentanol, 3-methyl-2pentanol $0.1 \mathrm{mg} / \mathrm{l} ; \gamma$-valerolactone $0.25 \mathrm{mg} / \mathrm{l}$; 2,5-dimethylfuran $0.2 \mathrm{mg} / \mathrm{l}$; and 2,5-hexanedione $0.4 \mathrm{mg} / \mathrm{l}$.

The mean recovery rate of the metabolites from urine when in a concentration of between $0.5-20 \mathrm{mg} / 1$ was: 2,5 -hexanedione $77 \%$, 2-hexanol $94 \%, 2,5$-dimethylfuran $78 \%, \gamma$-valerolactone $86 \%$, 2-methyl2-pentanol $81 \%$, and 3-methyl-2-pentanol $86 \%$.

The coefficients of variation for the amount of $15-20 \mathrm{mg} / \mathrm{l}$ of each metabolite added to urine were: 2,5 -hexanedione $2 \%, 2$-hexanol $4 \%, \gamma$-valerolactone $3 \%$, 3-methyl-2-pentanol $2 \%$, 2-methyl-2-pentanol $3 \%$, and 2,5 -dimethylfuran $10 \%(n=5)$. The urinary concentrations of hexane metabolites were corrected to a specific gravity of 1024 .

GAS-CHROMATOGRAPHIC CONDITIONS

The determination was performed with a Perkin Elmer F 17 gas chromatograph equipped with FID and two columns. The separation column consisted of $2-\mathrm{m}$ long stainless steel tubing (ID $2 \mathrm{~mm}$ ) filled with Carbopack C 80-100 mesh, coated with $0 \cdot 2 \%$ Carbowax 1500. Nitrogen was used as the carrier gas at a flow rate of $20 \mathrm{ml} / \mathrm{min}$. The column temperature was programmed from $125-140^{\circ} \mathrm{C} / \mathrm{min}$, the initial temperature remaining constant for $4 \mathrm{~min}$. The injector and detector temperature was $225^{\circ} \mathrm{C}$. The detectors were connected to a recorder Perkin Elmer model 56 (chart speed; $5 \mathrm{~mm} / \mathrm{min}$ ).

\section{Results}

In the environmental air of the shoe factories studied the following main solvents were found: n-hexane, 2-methylpentane and 3-methylpentane. Six other solvents (methylcyclopentane, cyclohexane, 2,3-dimethylbutane, acetone, dichloromethane, and trichloroethylene) were occasionally found at very low concentrations. The mean concentration of the main solvents determined in the three environmental samples collected for each worker individually was considered as representing the individual workers' environmental exposure. The distribution of environmental concentrations with regard to individual workers' exposure to the three main solvents is given in fig 1 .
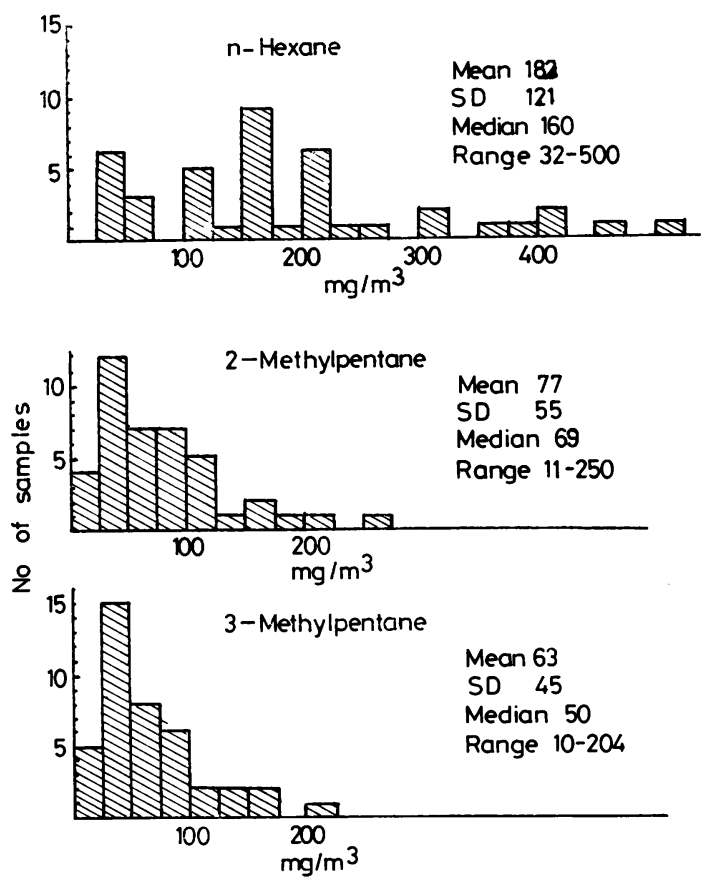

Fig 1 Distribution, mean, standard deviation (SD), median and range of environmental concentrations of n-hesane, 2-methylpentane, and 3-methylpentane. 


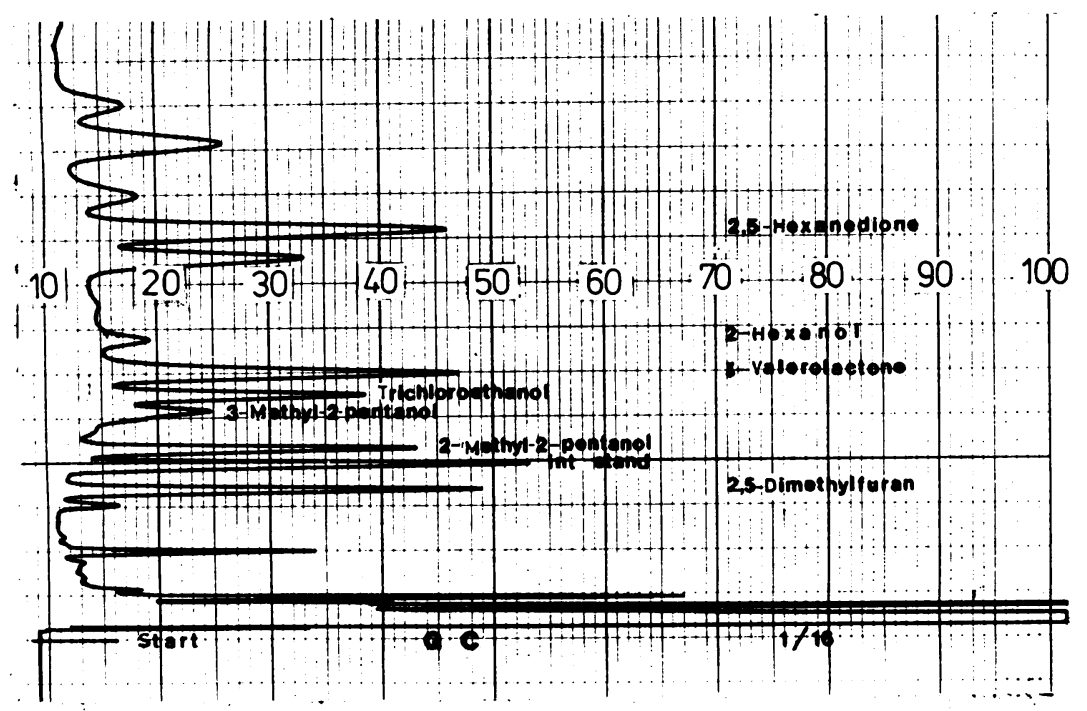

Fig 2 Gas chromatogram of urinary extract of $G C$.

Mean, standard deviation (SD), median and range of hexane metabolite concentration in workers' urine. Concentrations corrected to a specific gravity of 1024

\begin{tabular}{lllcl}
\hline Metabolites & $\begin{array}{l}\text { Mean } \\
(m g / l)\end{array}$ & $\begin{array}{l}S D \\
(m g / l)\end{array}$ & $\begin{array}{l}\text { Median } \\
(m g / l)\end{array}$ & $\begin{array}{l}\text { Range } \\
(m g / l)\end{array}$ \\
\hline 2-Methyl-2-pentanol & $1 \cdot 28$ & $1 \cdot 30$ & $0 \cdot 95$ & $<0 \cdot 1-5 \cdot 15$ \\
3-Methyl-2-pentanol & $0 \cdot 16$ & $0 \cdot 24$ & $<0 \cdot 1$ & $<0 \cdot 1 \cdot 1 \cdot 0$ \\
2,5-Hexanedione & $5 \cdot 4$ & $4 \cdot 9$ & $3 \cdot 9$ & $<0 \cdot 4-21 \cdot 7$ \\
2-Hexanol & $0 \cdot 19$ & $0 \cdot 26$ & $0 \cdot 12$ & $<0 \cdot 1-1 \cdot 2$ \\
2,5-Dimethylfuran & $3 \cdot 7$ & $4 \cdot 1$ & $2 \cdot 1$ & $0 \cdot 7-17 \cdot 5$ \\
$\gamma$-Valerolactone & $3 \cdot 3$ & $2 \cdot 7$ & $2 \cdot 2$ & $0 \cdot 7-11 \cdot 5$ \\
\hline
\end{tabular}

This figure also shows the mean, median, and range of concentrations of the three solvents tested. The environmental exposure to solvents ranged from 32 to $500 \mathrm{mg} / \mathrm{m}^{3}$ for $\mathrm{n}$-hexane, 11 to $250 \mathrm{mg} / \mathrm{m}^{3}$ for 2-methylpentane, and 10 to $204 \mathrm{mg} / \mathrm{m}^{3}$ for 3methylpentane. The mean concentration of $n$-hexane was $182 \mathrm{mg} / \mathrm{m}^{3}$ and its median $160 \mathrm{mg} / \mathrm{m}^{3}$. 2-Methylpentane and 3-methylpentane were present in lower concentrations than $\mathrm{n}$-hexane. The mean concentration of 2-methylpentane was $77 \mathrm{mg} / \mathrm{m}^{3}$ and its median $69 \mathrm{mg} / \mathrm{m}^{3}$; the mean concentration of 3-methylpentane was $63 \mathrm{mg} / \mathrm{m}^{3}$ and its median $50 \mathrm{mg} / \mathrm{m}^{3}$.

Figure 2 shows the gas chromatographic analysis of the urinary extract from one worker. 2-Methyl-2pentanol and 3-methyl-2-pentanol are detectable, together with the n-hexane metabolites: 2,5-hexanedione, 2-hexanol, $\gamma$-valerolactone, and 2,5-dimethylfuran. Figure 2 also shows a trichloroethanol peak that indicated a trichloroethylene exposure. In all the workers' urine the concentration of trichloroethanol, when present, was always lower than $25 \mathrm{mg} / \mathrm{l}$, which suggest that exposure to trichloroethylene exposure was low. 4

The mean, median, and range of urinary metabolite concentrations are given in the table. Although
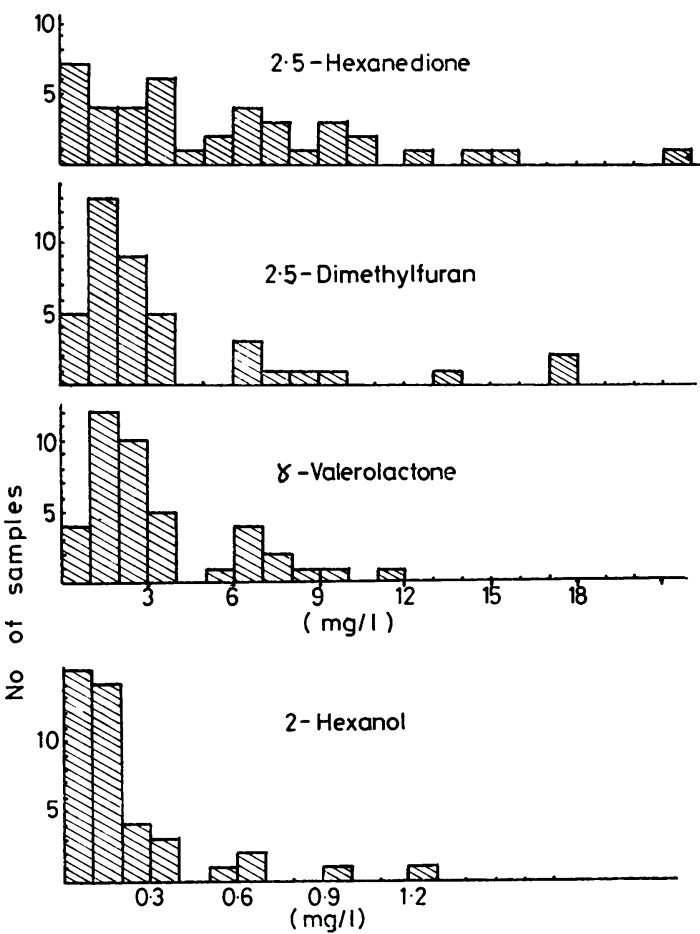

Fig 3 Distribution of urinary concentration of n-hexane metabolites. 
the mean concentrations of 2-methylpentane and 3-methylpentane in the environmental air were similar $\left(77\right.$ and $63 \mathrm{mg} / \mathrm{m}^{3}$ ), the mean urinary concentration of 2-methyl-2-pentanol $(1.28 \mathrm{mg} / \mathrm{l})$ was almost 10 times higher than that of 3-methyl-2pentanol $(0.16 \mathrm{mg} / \mathrm{l})$. The urinary concentration of 2-methyl-2-pentanol was lower than $0.1 \mathrm{mg} / \mathrm{l}$ in four out of 41 workers, that of 3-methyl-2-pentanol lower than $0 \cdot 1 \mathrm{mg} / \mathrm{l}$ in 23 workers.

As regards n-hexane metabolites, 2-hexanol showed the lowest mean and median urinary concentrations $(0 \cdot 19$ and $0 \cdot 12 \mathrm{mg} / \mathrm{l})$, while $2,5-$ hexanedione showed the highest $(5.4$ and $3.9 \mathrm{mg} / \mathrm{l})$. The urinary concentrations of 2,5-dimethylfuran and $\gamma$-valerolactone showed a similar mean and median: 3.7 and $2.1 \mathrm{mg} / \mathrm{l}$, and 3.3 and $2.2 \mathrm{mg} / \mathrm{l}$ respectively.

Figure 3 shows the distribution of n-hexane metabolite concentrations. The urinary concentration of 2-hexanol was lower than $0.1 \mathrm{mg} / \mathrm{l}$ in 15 out of 41 workers, that of 2,5-hexanedione lower than $0.4 \mathrm{mg} / \mathrm{l}$ in five workers; while 2,5-dimethylfuran and $\gamma$-valerolactone were always higher than their detectable limits in all the 41 workers' urine. The mean urinary concentration of 2-hexanol, 2,5hexanedione, 2,5-dimethylfuran, and $\gamma$-valerolactone corresponded to $1 \cdot 1 \%$ (SD 1.3), 36.5\% (SD 21.3), $30.5 \%$ (SD 16.8), and $31.9 \%$ (SD 16.1) of the total n-hexane metabolite concentration respectively. A wide variability in the percentage concentration of n-hexane metabolites was found. Nevertheless,

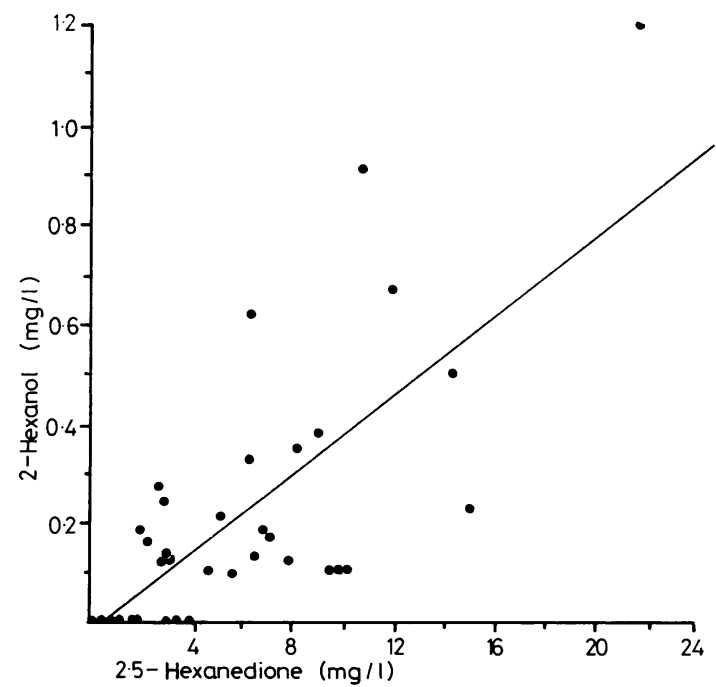

Fig 4 Relation between 2,5-hexanedione and 2-hexanol concentrations in workers' urine $(y=0.04 x-0.028$; $r=0.7448 ; n=41 ; p<0.001)$.

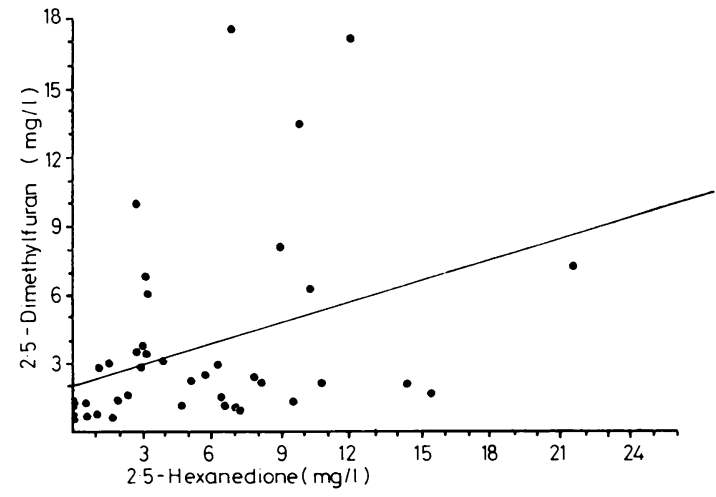

Fig 5 Relation between 2,5-hexanedione and 2,5dimethylfuran concentrations in workers' urine $(y=0.295 x+2 \cdot 11 ; r=0.3461 ; n=41 ; p<0.05)$.

2,5-hexanedione was in most cases the main metabolite.

The urinary concentration of 2,5-hexanedione was correlated with both 2-hexanol and 2,5-dimethylfuran (figs 4 and 5). No correlation was found among the other n-hexane metabolites.

The urinary products turned out to be correlated with the environmental concentrations of the parent solvents. Figure 6 shows that correlation between 2-methylpentane and 2-methyl-2-pentanol was highly significant $(\mathrm{r}=0.7588, \mathrm{p}<0.001)$. Figure 7 shows the correlation between environmental 3-methylpentane and urinary 3-methyl2-pentanol $(r=0.6513, p<0.001)$. Since the

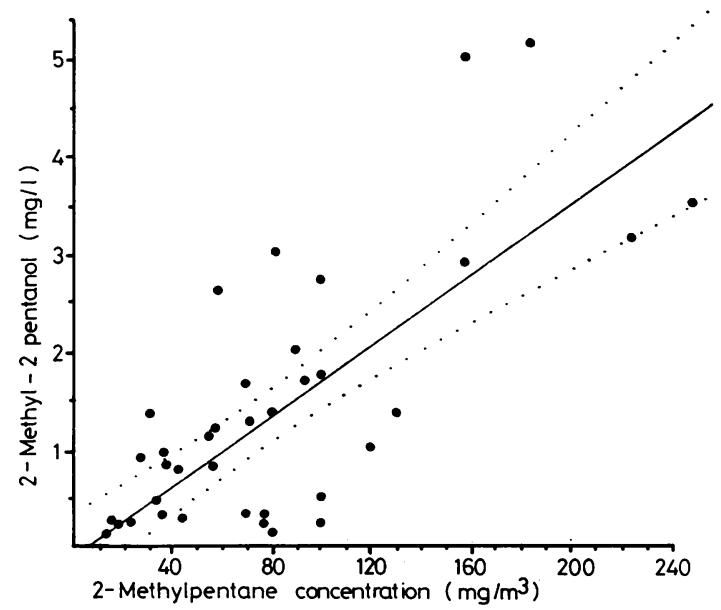

Fig 6 Correlation between environmental 2-methylpentane concentration and urinary concentration of 2-methyl-2-pentanol $(y=0.018 x-0.1 ; r=0.7588$; $n=41 ; p<0.001)$. 


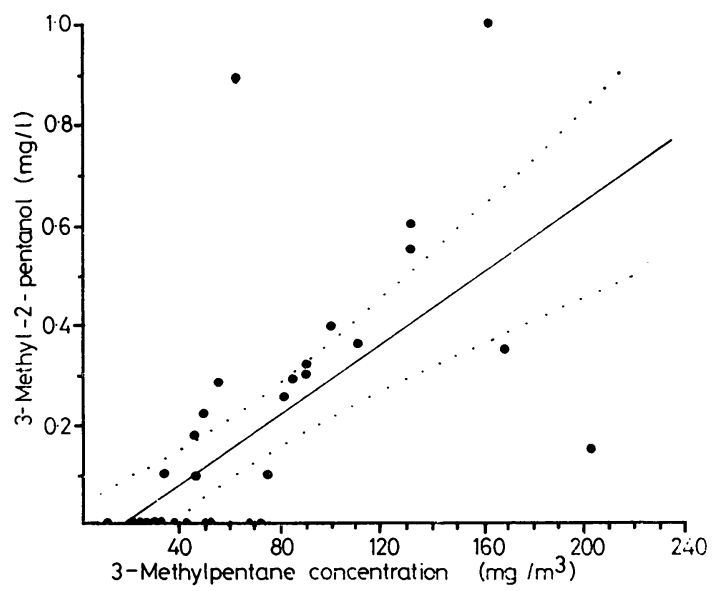

Fig 7 Correlation between environmental 3methylpentane concentration and urinary concentration of 3-methyl-2-pentanol $(y=0.0035 x-0.06 ; r=0.6513$, $n=41 ; p<0.001)$.

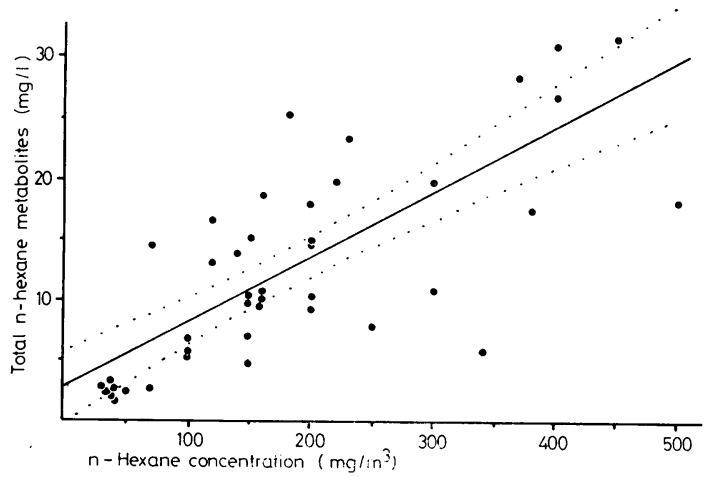

Fig 8 Correlation between environmental n-hexane concentration and urinary concentration of total n-hexane metabolites $(y=0.054 x+2 \cdot 7 ; r=0.7858 ; n=41$; $p<0.001)$.

3-methyl-2-pentanol in 23 out of 41 urine samples was lower than the minimum concentration detectable it is evident that many further tests are needed to confirm our results. All the n-hexane metabolites considered together were well correlated with n-hexane exposure (fig 8). Even individual nhexane metabolites were correlated with environmental n-hexane concentrations (figs 9-12). 2-Hexanol and 2,5-hexanedione were the metabolites best correlated with environmental exposure to $n$-hexane $(\mathrm{r}=0.6851$ and $\mathrm{r}=0.6725) .2,5$-Dimethylfuran and $\gamma$-valerolactone showed a lower correlation coefficient $(r=0.5012$ and $r=0.3991)$ than 2-hexanol

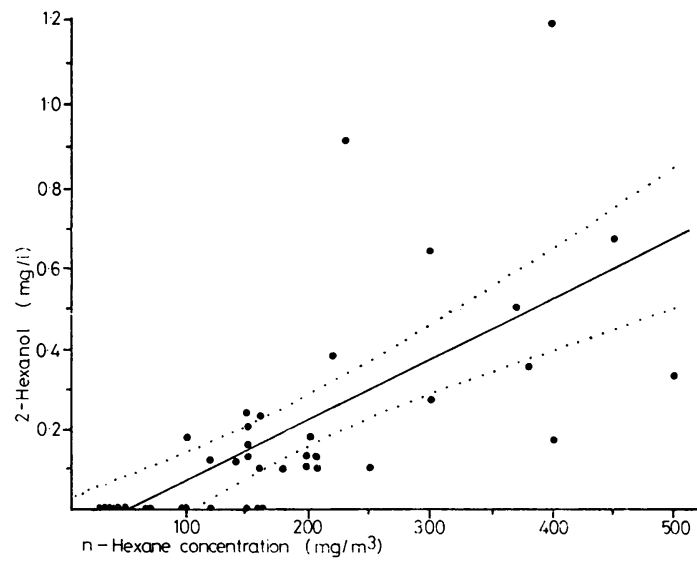

Fig 9 Correlation between environmental n-hexane concentration and urinary concentration of 2-hexanol $(y=0.0015 x-0.08 ; r=0.6851 ; n=41 ; p<0.001)$.

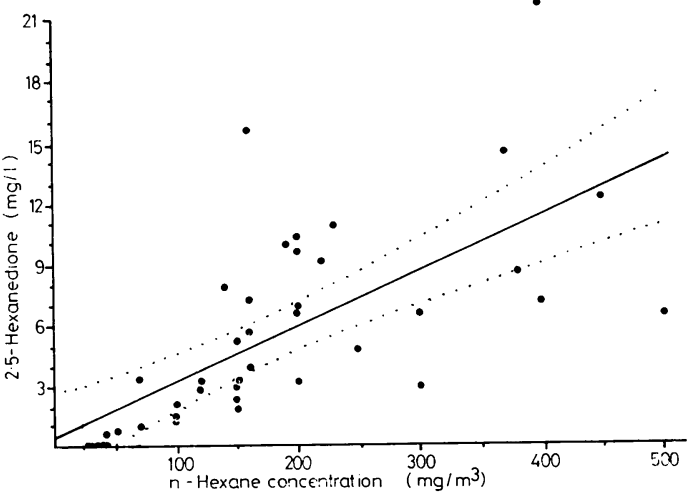

Fig 10 Correlation between environmental $n$-hexane concentration and urinary concentration of 2,5hexanedione $(y=0.027 x+0.49 ; r=0.6725 ; n=41$; $p<0.001)$.

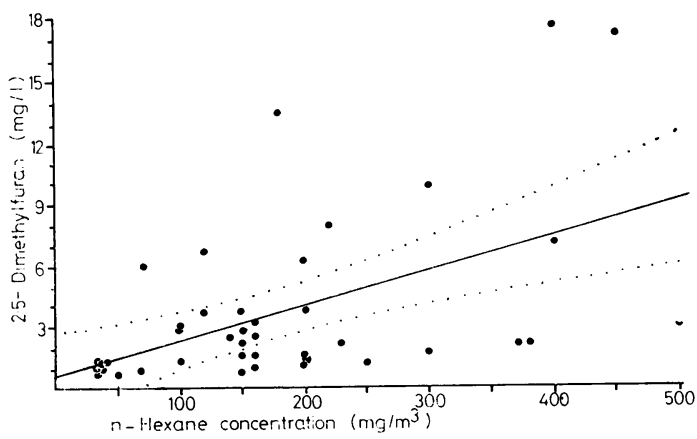

Fig 11 Correlation between environmental n-hexane concentration and urinary concentration of

2,5-dimethylfuran $(y=0.017 x+0 \cdot 59 ; r=0.5012$; $n=41 ; p<0.001)$. 


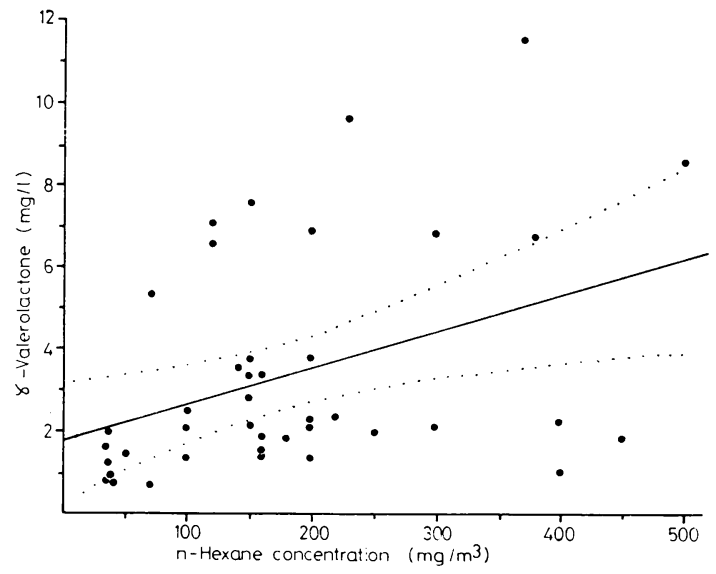

Fig 12 Correlation between environmental $n$-hexane concentration and urinary concentration of $\gamma$-valerolactone $(y=0.0089 x+1.73 ; r=0.3991 ; n=41$; $p<0.01)$.

and 2,5-hexanedione. Nevertheless, their correlation with $\mathrm{n}$-hexane environmental concentrations was significant $(\mathrm{p}<0.001$ and $\mathrm{p}<0.01$ respectively).

\section{Discussion}

The urinary metabolites found in the shoe factory workers exposed to commercial hexane are not detectable in the urine of non-exposed people. This observation suggests that the determination of n-hexane metabolites could be used to monitor occupational exposure. According to studies carried out on experimental animals ${ }^{5}$ and in man, ${ }^{3}$ the metabolism of n-hexane and methyl-n-butyl ketone is closely connected (fig 13), so that the four compounds 2-hexanol, 2,5-hexanedione, 2,5-dimethylfuran, and $\gamma$-valerolactone are likely to be produced after exposure to both n-hexane and methyl-n-butyl ketone. All these metabolites have been identified in animals exposed to methyl-n-butyl ketone; 6 2,5-hexanedione was found in the serum but not in the urine of people experimentally exposed to methyl-n-butyl ketone. On the other hand all four of the metabolites were found after exposure to $\mathrm{n}$-hexane both in animals (N Frontali et al at the International Congress of Neurotoxicology in Varese, Italy, 27-30 September 1979) and in man. ${ }^{3}$

Examination of our data (fig 8) shows that at the $95 \%$ confidence level an n-hexane exposure of $90 \mathrm{mg} / \mathrm{m}^{3}$ (TLV proposed by ACGIH 1979) corresponded with a urinary excretion of $5 \cdot 5-9 \cdot 7 \mathrm{mg} / \mathrm{l}$ of total n-hexane metabolites. For each of the individual n-hexane metabolites, the urinary excretion corresponding to an n-hexane exposure of $90 \mathrm{mg} / \mathrm{m}^{3}$ was $0-1.3 \mathrm{mg} / \mathrm{l}$ for 2-hexanol, $0.8-3.7 \mathrm{mg} / \mathrm{l}$ for 2,5-dimethylfuran, $1 \cdot 5-3 \cdot 5 \mathrm{mg} / \mathrm{l}$ for $\gamma$-valerolactone, and $1 \cdot 5-4 \cdot 4 \mathrm{mg} / \mathrm{l}$ for 2,5-hexanedione (figs 9-12).

As regards the correlations between the environmental exposure to $n$-hexane and its urinary metabolites, our data show that 2-hexanol and 2,5-hexanedione correlated more positively $(r=0.6851$ and $r=0.6725$ ) than 2,5-dimethylfuran and $\gamma$-valerolactone $(r=0.5012$ and $r=0.3991)$. The latter compounds are probably not "true metabolites" but products formed by cyclisation of hydroxylated precursor during gas-chromatographic analysis.?

Thus it seems reasonable that 2-hexanol and 2,5-hexanedione might be used as reliable indicators for monitoring environmental exposure to nhexane. From the practical point of view, 2,5hexanedione, which shows higher urinary concentrations than 2-hexanol, must probably be considered as more reliable than 2-hexanol. The urinary concentration of total n-hexane metabolites correlated well with environmental $n$-hexane concentrations $(r=0 \cdot 7858)$.

The urinary excretion of 2-methyl-2-pentanol and 3-methyl-2-pentanol and their statistical correlations to environmental exposure to 2-methylpentane and

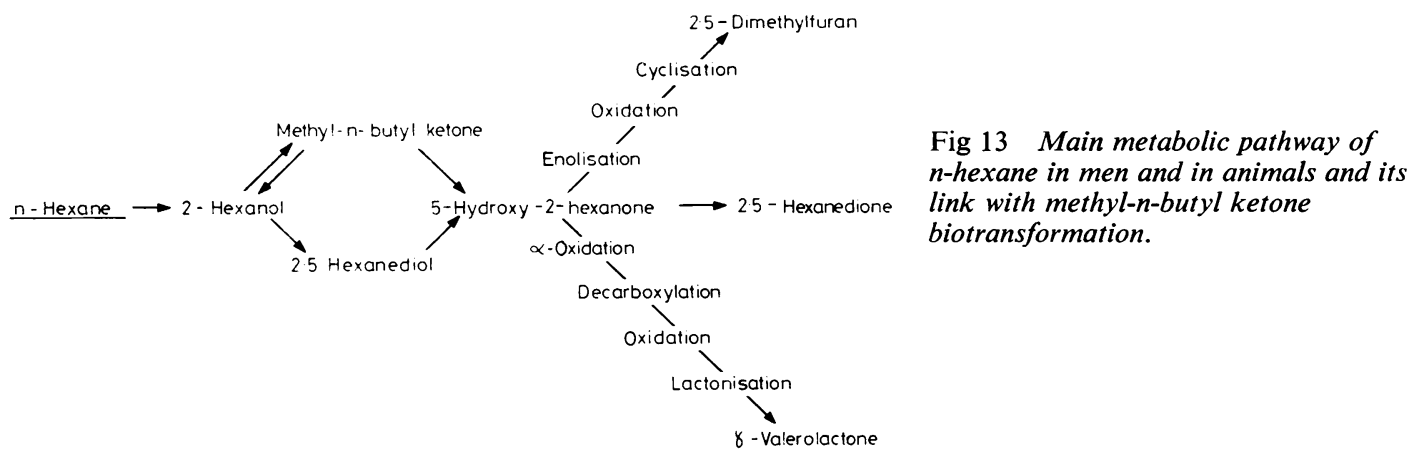


3-methylpentane respectively suggest that occupational exposure to the latter may also be monitored by means of urinary tests.

By comparing the slope of the regression line in figs 6,7 , and 8 , it emerges that with the same environmental concentrations of the three solvents the concentration of all $n$-hexane metabolites taken together is three and 15 times higher than that of 2-methyl-2-pentanol and 3-methyl-2-pentanol respectively.

As regards the n-hexane exposure, our results showed that 2-hexanol and 2,5-hexanedione were the least and the most important metabolites respectively. This finding differs from the results from animal experiments in which 2-hexanol is the main metabolite of $n$-hexane. ${ }^{8}{ }^{9}$ This could suggest a higher susceptibility to $n$-hexane neurotoxicity in man than in animals. Experimental studies showed that 2,5-hexanedione causes an inhibition of glycolytic enzyme activity (phosphofructokinase, glyceraldehyde-3-phosphate dehydrogenase and $\alpha$ glycerophosphate dehydrogenase) in nerve fibres, which could be the primary cause of hexacarbon neuropathies. ${ }^{10}$

\section{References}

${ }^{1}$ Brugnone F, Perbellini L, Grigolini L, Apostoli P. Solvent exposure in a shoe upper factory. I n-Hexane and acetone concentration in alveolar and environmental air and in blood. Int Arch Occup Environ Health 1978;42: $51-62$.

${ }^{2}$ Brugnone F, Perbellini L, Grigolini L, Apostoli P. Solvent exposure in a shoe upper factory. II Methylcyclopentane, 2-methylpentane and 3-methylpentane concentration in alveolar and environmental air and in blood. Int Arch Occup Environ Health 1979;42:355-63.

${ }^{3}$ Perbellini L, Brugnone F, Pavan I. Identification of the metabolites of n-hexane, cyclohexane and their isomers in men's urine. Toxicol Appl Pharm 1980;53:220-9.

+ Guberan E. Proposed biological threshold limit values for industrial exposure to trichloroethylene vapor. Scand $J$ Work Environ Health 1977;3:80-90.

${ }^{5}$ Di Vincenzo GD, Kaplan CJ, Dedinas J. Characterization of the metabolites of methyl-n-butyl ketone, methylisobutyl ketone, and methylethyl ketone in guinea-pig serum and their clearance. Toxicol Appl Pharm 1976;36 511-22.

${ }^{6}$ Di Vincenzo GD, Hamilton ML, Kaplan CJ, Krasavage WJ, O'Donoghue JL. Studies on the respiratory uptake and excretion and the skin absorption of methyl-n-buty ketone in humans and in dog. Toxicol Appl Pharm 1978 44:593-604.

'Di Vincenzo GD, Hamilton ML, Kaplan CJ, Dedinas J. Metabolic fate and disposition of $14 \mathrm{C}$-labelet methyl-nbutyl ketone in the rat. Toxicol Appl Pharm 1977;41: 547-60.

8 Abdel-Rahman MS, Hetland LB, Couri D. Toxicity and metabolism of methyl-n-butyl ketone. Am Ind Hyg Assoc $J$ 1976;2:95-102.

9 Perbellini L, Brugnone F, Pastorello G, Grigolini L. Urinary excretion of $\mathrm{n}$-hexane metabolites in rats and humans. Int Arch Occup Environ Health 1979;42:349-54.

${ }^{10}$ Spencer PS, Sabri MI, Schaumburg HH, Moore CL. Does a defect of energy metabolism in the nerve fiber underlie axonal degeneration in polyneuropathies? Ann Neuro $1979 ; 5: 501-7$. 